University of Texas at El Paso

ScholarWorks@UTEP

\title{
Kekule's Benzene Structure: A Case Study of Teaching Usefulness of Symmetry
}

Olga Kosheleva

The University of Texas at El Paso, olgak@utep.edu

Vladik Kreinovich

The University of Texas at El Paso, vladik@utep.edu

Follow this and additional works at: https://scholarworks.utep.edu/cs_techrep

Part of the Applied Mathematics Commons

Comments:

Technical Report: UTEP-CS-14-58

Published in Applied Mathematical Sciences, 2014, Vol. 8, No. 144, pp. 7183-7194.

\section{Recommended Citation}

Kosheleva, Olga and Kreinovich, Vladik, "Kekule's Benzene Structure: A Case Study of Teaching Usefulness of Symmetry" (2014). Departmental Technical Reports (CS). 889.

https://scholarworks.utep.edu/cs_techrep/889

This Article is brought to you for free and open access by the Computer Science at ScholarWorks@UTEP. It has been accepted for inclusion in Departmental Technical Reports (CS) by an authorized administrator of ScholarWorks@UTEP. For more information, please contact Iweber@utep.edu. 


\title{
Kekulé's Benzene Structure: A Case Study of Teaching Usefulness of Symmetry
}

\author{
Olga Kosheleva ${ }^{1}$ and Vladik Kreinovich ${ }^{2}$ \\ ${ }^{1}$ Department of Teacher Education \\ ${ }^{2}$ Department of Computer Science \\ University of Texas at El Paso \\ $500 \mathrm{~W}$. University \\ El Paso, TX 79968, USA \\ olgak@utep.edu,vladik@utep.edu
}

\begin{abstract}
Benzene is one of the basic building blocks of organic molecules. One of the reasons for benzene's ubiquity is its unusual ring structure first discovered by Kekulé in 1865 . In this paper, we show that a simple symmetry-based analysis can narrow down possible benzene structures to three ring ones, including the Kekulé's ring. Thus, Kekulé's benzene structure provides a good pedagogical example on which one can explain usefulness of symmetries.
\end{abstract}

\section{Kekule's Benzene Structure: Reminder}

The importance of benzene. Hydrocarbons are extremely important molecules: they form the basis of oil, our civilization's current main source of energy; they form the basic of energy processes in biological systems, etc. From the chemical viewpoint, most hydrocarbons are composed of one or several benzene rings. Thus, benzene $\mathrm{C}_{6} \mathrm{H}_{6}$ itself - the simplest of such molecules - can be viewed as one of the most basic of the hydrocarbons.

How the chemical structure of benzene was determined. The importance of benzene was recognized already in the 19th century. Because of this importance, several researchers proposed possible schemes for benzene's chemical structure; see, e.g., [1, 2, 3, 11, 12, 13].

A breakthrough was achieved in 1865, when a German chemist Friedrich August Kekulé proposed the currently accepted ring structure [7]; see also [8, 9, 10]. In this structure, six Carbon atoms form a ring, and a Hydrogen atom is attached to each of these Carbon atoms. 


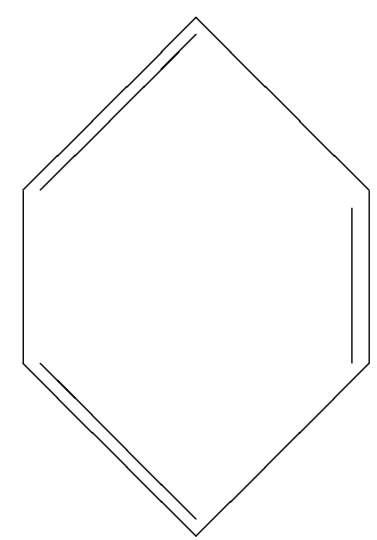

This picture remains, in effect, the modern description of benzene, with the only difference that due to quantum effects, there are no longer separate single and double bonds, each bond is a superposition of bonds of both type.

Comment. It is worth mentioning that one of the possible explanations for ubiquity of hexagon-shaped benzene configurations is that the hexagonal tiling is the best way to divide a surface into regions of equal area with the least total perimeter. This statement was formulated more than 2,000 years ago as a conjecture, and it was proved only in 1999 [5]; the same statement explains hexagonal tiling structure of beehives and of graphene, material behind carbon nanotubes; see, e.g., [6, 17].

How did Kekule come up with his idea. One of the main motivations for Kekule was the idea of symmetry. Symmetry properties come from analyzing mono- and di-substituted molecules, in which one or two Hydrogen or Carbon atoms are replaced with other atoms - or with more complex atomic combinations (called ligands).

For example, the fact that for the same ligand replacing Carbon, there is only one type of molecule (i.e., that chemical properties do not depend on which Carbon atom is replaced), is an indication that all $\mathrm{C}$ atoms in this molecule are equivalent to each other - i.e., that for every two Carbon atoms, there is a permutation of this structure which transforms the first $\mathrm{C}$ atom into the second one.

Kekule did not just use the notion of symmetry. According to Kekule himself, his idea of a ring was also due to an inspiration - inspired by a vision of a snake seizing its own tail [10].

Comments. A detailed history of Kekule's discovery can be found in $[14,15,16$, $18]$.

\section{Formulation of the Problem}

Is it possible to only use symmetry? In his discovery, Kekule used both symmetry and inspiration. Now that we know how important symmetry is in 
modern physics (see, e.g., [4]), a natural question is: is it possible to only use symmetry?

Why this is a pedagogically interesting question? This is a relatively simple real-life problem, on which one can trace symmetries without having to know too much mathematics.

What we do in this paper. In this paper, we describe all possible benzene structures which have the desired symmetry. We will show that there only three such structures (and all three have rings).

\section{Analysis of the Problem and Resulting Possi- ble Structures of a $\mathrm{C}_{6} \mathrm{H}_{6}$ Molecule}

Molecule: reminder. We have six Carbon $(\mathrm{C})$ atoms and six Hydrogen $(\mathrm{H})$ atoms. We want to describe how these 12 atoms can be connected by bonds to form a single molecule.

Being a molecule means that, by following these bounds, we can go from each of these 12 atoms to every other of these atoms - as opposed to situations in which we have two different molecules, with no bonds between them.

Valence: reminder. Carbon $\mathrm{C}$ has valence 4, Hydrogen $\mathrm{H}$ has valence 1. This means that in a molecule, each $\mathrm{C}$ atom has 4 bounds, and each $\mathrm{H}$ atom has a single bound.

Symmetry: reminder. We know that in the desired molecules, all six atoms $\mathrm{C}$ are equivalent - in the sense for every two of these atoms, there is a transformation that transforms the first one into the second one while preserving the structure.

Comment. One can easily observe that this requirement is satisfied for the Kekule structure.

Observation about $\mathbf{H}$ atoms. Each $\mathrm{H}$ atom has valence 1 and thus, can be connected to only one other atom.

If this $\mathrm{H}$ atom is connected to another $\mathrm{H}$ atom, then both of them exhausted their valence, so neither of them can be connected to anything else. As a result, these two $\mathrm{H}$ atoms form a separate molecule

$$
\mathrm{H}-\mathrm{H} \text {, }
$$

while we are looking for configurations in which all 12 atoms form a single molecule.

Thus, in the desired molecular arrangement, each $\mathrm{H}$ atom cannot be connected to another $\mathrm{H}$ atom and therefore, has to be connected to a $\mathrm{C}$ atom.

How many $\mathrm{H}$ atoms are connected to each $\mathrm{C}$ atom: let us apply symmetry. Since all six C atoms are equivalent to each other, each of them has 
the exact same number of $\mathrm{H}$ atoms connected to it. Let us denote this number by $n$. The total number of $\mathrm{H}$ atoms in the molecule can thus be determined as $n$ multiplied by six.

Overall, we have $6 n=6 \mathrm{H}$ atoms, so $n=1$ and therefore, each $\mathrm{C}$ atom is connected to exactly one $\mathrm{H}$ atom.

Resulting convenient notation. We know that each $\mathrm{C}$ atom is connected to exactly one $\mathrm{H}$ atom. Thus, to simplify our notations, we will follow the usual convention of picturing only $\mathrm{C}$ atoms - with the understanding that, in addition to six explicitly drawn $\mathrm{C}$ atoms, there are also six $\mathrm{H}$ atoms, each of which is connected to one of the $\mathrm{C}$ atoms.

In principle, we can have single, double, or triple bonds. Each $\mathrm{C}$ atom is connected to one $\mathrm{H}$ atom, which leaves 3 out of 4 bonds to connect to other $\mathrm{C}$ atoms. In principle, there are three possibilities:

- it can be that one of the $\mathrm{C}$ atoms has a triple bond to some other $\mathrm{C}$ atom:

$$
\mathrm{C} \equiv \mathrm{C}
$$

- it can also be that there are no triple bonds, but some $\mathrm{C}$ atoms are connected by a double bond

$$
\mathrm{C}=\mathrm{C} \text {; }
$$

- it is also possible that all the bonds are singular

$$
\mathrm{C}-\mathrm{C} \text {. }
$$

Let us consider all these three cases one by one.

Case of a triple bond. If two $\mathrm{C}$ atoms are connected by a triple bond, then they have no bonds left to connect to other $\mathrm{C}$ atoms. In this case, instead of being part of a 12-atom molecule, these two atoms will form a separate molecule:

$$
\mathrm{C} \equiv \mathrm{C}
$$

Thus, if all 12 atoms form a molecules, triple bonds between $\mathrm{C}$ atoms are impossible.

Case of a double bond. Let us now assume that two $\mathrm{C}$ atoms are connected by a double bond $\mathrm{C}=\mathrm{C}$. For convenience, let us denote these atoms by $\mathrm{C}(1)$ and $\mathrm{C}(2)$, then we have

$$
\mathrm{C}(1)=\mathrm{C}(2)
$$

Since the atom $\mathrm{C}(1)$ has 3 bonds to connect to other $\mathrm{C}$ atoms, and it only uses two of them to connect to $\mathrm{C}(2)$, thus the remaining bond connects $\mathrm{C}(1)$ with some other atom; let us denote this other atom by $\mathrm{C}(3)$ :

$$
\mathrm{C}(3)-\mathrm{C}(1)=\mathrm{C}(2)
$$


Similarly, C(2) must use its remaining bond to connect to some other C atom. This other atom cannot be $\mathrm{C}(1)$ - we already described all the bonds between $\mathrm{C}(1)$ and $\mathrm{C}(2)$. This also cannot be $\mathrm{C}(3)$, because then $\mathrm{C}(3)$ would have a single bond connection with two $\mathrm{C}$ atoms - and thus, it will not be equivalent to $\mathrm{C}(1)$ which has one double and one single connection. So, the $\mathrm{C}$ atom to which $\mathrm{C}(1)$ is singly bounded must be different from $\mathrm{C}(1), \mathrm{C}(2)$, and $\mathrm{C}(3)$. Let us denote this atom by $\mathrm{C}(4)$. As a result, we get the following configuration:

$$
\mathrm{C}(3)-\mathrm{C}(1)=\mathrm{C}(2)-\mathrm{C}(4)
$$

All the $\mathrm{C}$ atoms are equivalent to each other. The atom $\mathrm{C}(1)$ has one single and one double connection; thus, the atom $\mathrm{C}(3)$ should also have, in addition to its single connection (to $\mathrm{C}(1)$ ), a double connection. This double connection cannot be to $\mathrm{C}(1)$ or to $\mathrm{C}(2)$, since these two atoms have no valence left. It cannot be to $\mathrm{C}(4)$, because then, all four atoms $\mathrm{C}(1), \mathrm{C}(2), \mathrm{C}(3)$, and $\mathrm{C}(4)$ would exhaust their valence and thus, form a molecule of four $\mathrm{C}$ atoms. Therefore, the double connection from $\mathrm{C}(3)$ has to be to some $\mathrm{C}$ atom which is different from $\mathrm{C}(1), \mathrm{C}(2)$, or $\mathrm{C}(4)$. Let us denote this $\mathrm{C}$ atom (which is doubly connected to $\mathrm{C}(3))$ by $\mathrm{C}(5)$ :

$$
\mathrm{C}(5)=\mathrm{C}(3)-\mathrm{C}(1)=\mathrm{C}(2)-\mathrm{C}(4)
$$

Similarly, $\mathrm{C}(4)$ has to have a double connection to some $\mathrm{C}$ atom. This connection cannot be with $\mathrm{C}(1), \mathrm{C}(2), \mathrm{C}(3)$, or $\mathrm{C}(5)$ : none of them has enough valence. Thus, the connection has to be to a different $\mathrm{C}$ atom; let us denote this atom by $\mathrm{C}(6)$ :

$$
\mathrm{C}(5)=\mathrm{C}(3)-\mathrm{C}(1)=\mathrm{C}(2)-\mathrm{C}(4)=\mathrm{C}(6)
$$

Now, the only two atoms that have unused bonds are $\mathrm{C}(5)$ and $\mathrm{C}(6)$. So, the only way to connect these two remaining bonds is if $\mathrm{C}(5)$ has a single bond with $\mathrm{C}(6)$. Thus, we arrive at Kekulé's ring structure.

Case when all bonds are single. Let us now consider the remaining case when all the bonds between $\mathrm{C}$ atoms are single bonds. Let us start with some $\mathrm{C}$ atom; we will denote it by $\mathrm{C}(1)$. This atom has three bonds to connect to other $\mathrm{C}$ atoms. Since all these bonds are single, $\mathrm{C}(1)$ is thus connected to three other atoms; let us denote them $\mathrm{C}(2), \mathrm{C}(3)$, and $\mathrm{C}(4)$.

Let us consider two subcases: when none of the three atoms $\mathrm{C}(2), \mathrm{C}(3)$, and $\mathrm{C}(4)$ are connected to each other, and when at least of these three atoms are connected to each other.

Subcase 1: no triangles. Let us start with a subcase in which none of the three atoms $\mathrm{C}(2), \mathrm{C}(3)$, and $\mathrm{C}(4)$ are connected to each other. In this case, $\mathrm{C}(1)$ is not a part of any triangle of bonds. Since all the $\mathrm{C}$ atoms are equivalent to each other, we thus conclude that the resulting molecular structure has no triangle at all.

Now, $\mathrm{C}(2)$ has three bonds; one of these bonds is used to connect it to $\mathrm{C}(1)$, so two bonds remain. These bonds cannot connect $\mathrm{C}(2)$ to $\mathrm{C}(3)$ or $\mathrm{C}(4)$ since this would form a triangle. Thus, $\mathrm{C}(2)$ is singly connected to two other atoms; we will denote them $\mathrm{C}(5)$ and $\mathrm{C}(6)$. 
Similarly, $\mathrm{C}(3)$ has two remaining connections to $\mathrm{C}$ atoms. These remaining connections cannot be to $\mathrm{C}(1), \mathrm{C}(2)$, or $\mathrm{C}(4)$, so they must be to the two remaining $\mathrm{C}$ atoms $\mathrm{C}(5)$ and $\mathrm{C}(6)$.

Likewise, $\mathrm{C}(4)$ must be singly connected to $\mathrm{C}(5)$ and $\mathrm{C}(6)$. Now:

- $\mathrm{C}(1)$ is connected to $\mathrm{C}(2), \mathrm{C}(3)$, and $\mathrm{C}(4)$;

- $\mathrm{C}(2)$ is connected to $\mathrm{C}(1), \mathrm{C}(5)$, and $\mathrm{C}(6)$;

- $\mathrm{C}(3)$ is connected to $\mathrm{C}(1), \mathrm{C}(5)$, and $\mathrm{C}(6)$;

- $\mathrm{C}(4)$ is connected to $\mathrm{C}(1), \mathrm{C}(5)$, and $\mathrm{C}(6)$;

- $\mathrm{C}(5)$ is connected to $\mathrm{C}(2), \mathrm{C}(3)$, and $\mathrm{C}(4)$;

- $\mathrm{C}(6)$ is connected to $\mathrm{C}(2), \mathrm{C}(3)$, and $\mathrm{C}(4)$.

We can see that the six $\mathrm{C}$ atoms can be divided into two groups:

- the first group is formed by the atoms $\mathrm{C}(1), \mathrm{C}(5)$, and $\mathrm{C}(6)$;

- the second group is formed by the atoms $\mathrm{C}(2), \mathrm{C}(3)$, and $\mathrm{C}(4)$.

Each atom from the first group is connected with each atom from the second group.

In particular, $\mathrm{C}(1)$ is connected to $\mathrm{C}(2)$ which is connected to $\mathrm{C}(5)$ which is connected to $\mathrm{C}(3)$ which is connected to $\mathrm{C}(6)$ which is connected to $\mathrm{C}(4)$ which is connected to $\mathrm{C}(1)$. In the resulting ring, each $\mathrm{C}$ atom is connected to each of its direct neighbors, and also to its opposite atom: $\mathrm{C}(1)$ is connected to $\mathrm{C}(3)$, $\mathrm{C}(2)$ to $\mathrm{C}(6)$, and $\mathrm{C}(4)$ to $\mathrm{C}(5)$ :

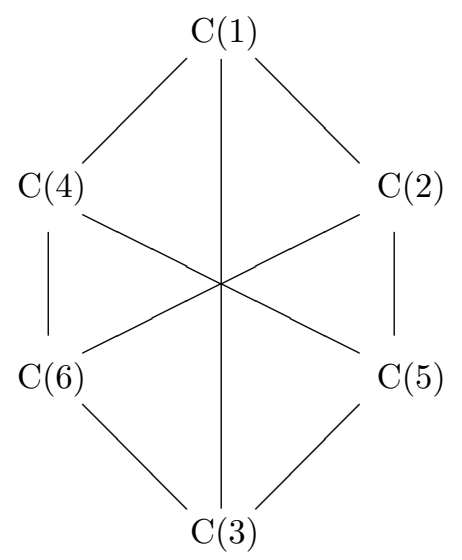

As a result, we get a ring structure originally proposed by A. K. L. Claus [2]. 


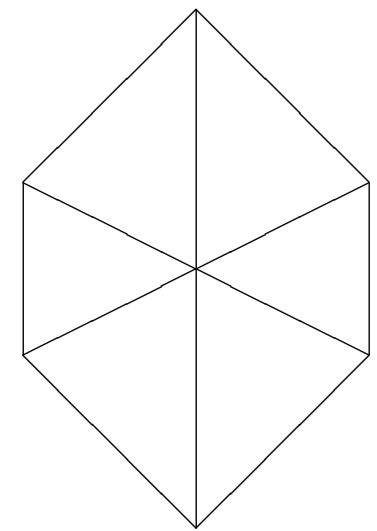

Subcase 2: triangles. Let us now consider the case when three of the $\mathrm{C}$ atoms are connected to each other forming a triangle. Let us denote these atoms by $\mathrm{C}(1), \mathrm{C}(2)$, and $\mathrm{C}(3)$ :

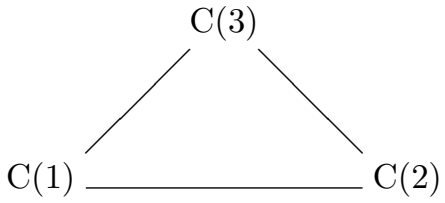

Since all the $\mathrm{C}$ atoms are equivalent to each other, the fact that one of these atoms is part of a triangle means that each $\mathrm{C}$ atom is part of a triangle. Thus, since the triangle consisting of $\mathrm{C}(1), \mathrm{C}(2)$, and $\mathrm{C}(3)$ only contains 3 atoms, there should be at least one other triangle.

Let us analyze possible relations between different triangles. In principle, two different triangles can have 0,1 , or 2 vertices in common. Let us analyze these possibilities one by one.

Subcase 2.1. Two triangles share a single vertex. Let us first show, by contradiction, that two triangles cannot have one single common vertex. Indeed, in this case, this common vertex is connected to four different $\mathrm{C}$ atoms:

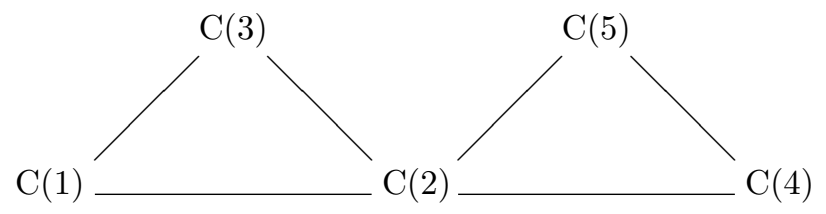

and we have already explained that each $\mathrm{C}$ atoms is only connected to three different $\mathrm{C}$ atoms. The contradiction shows that this case is indeed impossible.

Subcase 2.2. Two triangles share two common vertices. In this case, the two triangle have a common edge. Let us show that this case is also impossible. 
Indeed, let us denote the $\mathrm{C}$ atoms from the common edge by $\mathrm{C}(1)$ and $\mathrm{C}(2)$, and the third vertices of the corresponding triangles by $\mathrm{C}(3)$ and $\mathrm{C}(4)$. Under these notations, we have the following configuration:

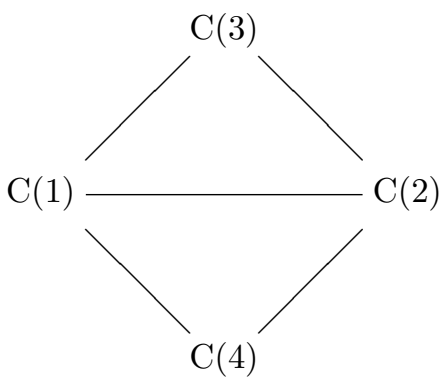

Here, $\mathrm{C}(4)$ is connected to $\mathrm{C}(1)$ and to $\mathrm{C}(2)$. Since each $\mathrm{C}$ atom has three connections to $\mathrm{C}$ atoms, the atom $\mathrm{C}(4)$ must be connected to one other $\mathrm{C}$ atom. The atom $\mathrm{C}(4)$ cannot be connected to $\mathrm{C}(3)$, since then all 4 atoms have exhausted their connections, and these four atoms $\mathrm{C}(1), \mathrm{C}(2), \mathrm{C}(3)$, and $\mathrm{C}(4)$ would form a molecule unconnected to the two remaining $\mathrm{C}$ atoms. Thus, the third connection of $\mathrm{C}(4)$ should be to some $\mathrm{C}$ atom which is different from $\mathrm{C}(1)$, $\mathrm{C}(2)$, and $\mathrm{C}(3)$. Let us denote this $\mathrm{C}$ atom - which is connected to $\mathrm{C}(4)$ - by $\mathrm{C}(5)$. We thus get the following configuration:

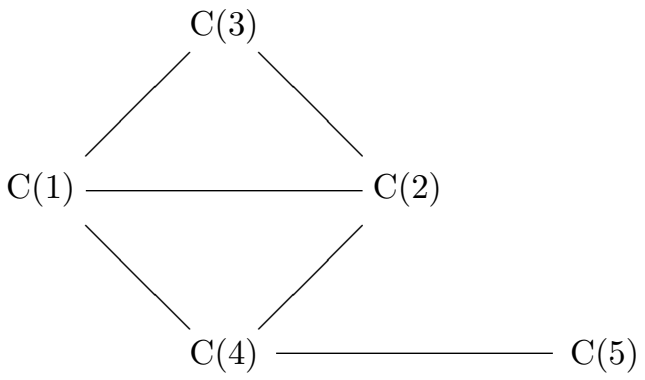

For the atom $\mathrm{C}(1)$, among the three $\mathrm{C}$ atoms $\mathrm{C}(2), \mathrm{C}(3)$, and $\mathrm{C}(4)$ to which it is connected, two pairs are connected to each other: $\mathrm{C}(2)$ is connected to $\mathrm{C}(3)$, and $\mathrm{C}(2)$ is connected to $\mathrm{C}(4)$. Since all $\mathrm{C}$ atoms are equivalent to each other, the same property should hold for $\mathrm{C}(4)$ : among the three $\mathrm{C}$ atoms $\mathrm{C}(1), \mathrm{C}(2)$, and $\mathrm{C}(5)$ to which it is connected, two pairs should be connected to each other. We already know that $\mathrm{C}(1)$ is connected to $\mathrm{C}(2)$, so $\mathrm{C}(5)$ must be connected to either $\mathrm{C}(1)$ or $\mathrm{C}(2)$. However, this is not possible, since neither $\mathrm{C}(1)$ not $\mathrm{C}(2)$ have any valences left. Thus, this subcase is also impossible. 
This leaves the only remaining subcase.

Subcase 2.3. No two triangles have common vertices. We have already mentioned that we must have at least two triangles. Since two different triangles do not have common vertices, this means that all six vertices of these two triangles are different, so all six $\mathrm{C}$ atoms are elements of these two triangle. Let us denote the $\mathrm{C}$ atoms from the first triangle by $\mathrm{C}(1), \mathrm{C}(2)$, and $\mathrm{C}(3)$. The remaining three atoms also form a triangle.

The atom $\mathrm{C}(1)$ is connected to $\mathrm{C}(2)$ and $\mathrm{C}(3)$. The atom $\mathrm{C}(1)$ must be connected to three $\mathrm{C}$ atoms, so the third $\mathrm{C}$ atom to which $\mathrm{C}(1)$ is connected is outside the first triangle; let us denote this atom by $\mathrm{C}(4)$.

Similarly, the atom $\mathrm{C}(2)$ must be connected to an atom outside the first triangle; let us denote this atom by $\mathrm{C}(5)$. Finally, the atom $\mathrm{C}(3)$ must be connected to an atom outside the first triangle; we will denote this atom by $\mathrm{C}(6)$. As a result, we arrive at the following configuration:

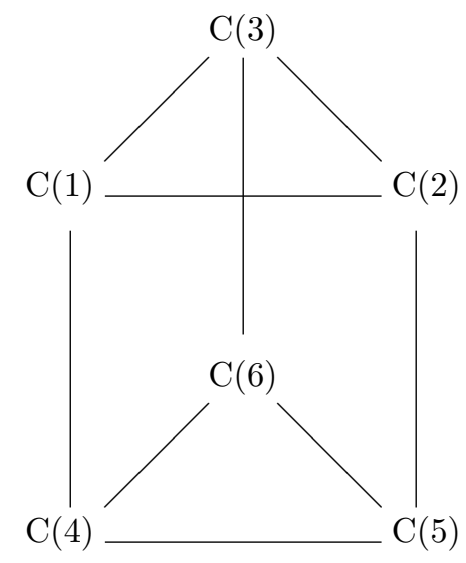

i.e., a configuration first proposed by A. Ladenburg in [11]:

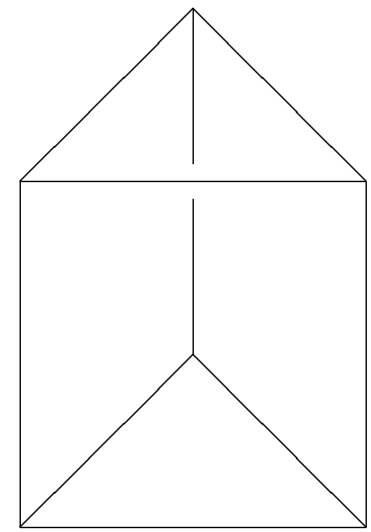


Conclusion. Under the assumption of symmetry - that all $\mathrm{C}$ atoms are equivalent to each other - there are exactly three possible configurations of the molecule $\mathrm{C}_{6} \mathrm{H}_{6}$ : Kekule's ring and the ring configurations proposed by Claus and Ladenburg.

All three possible symmetric configurations contain rings:

- Kekule's configuration contains a single ring of size 6;

- Claus's configuration contains several rings of size 4:

$$
\begin{gathered}
\mathrm{C}(1)-\mathrm{C}(2)-\mathrm{C}(5)-\mathrm{C}(3), \mathrm{C}(1)-\mathrm{C}(4)-\mathrm{C}(6)-\mathrm{C}(3), \\
\mathrm{C}(1)-\mathrm{C}(2)-\mathrm{C}(5)-\mathrm{C}(4), \mathrm{C}(1)-\mathrm{C}(2)-\mathrm{C}(6)-\mathrm{C}(4), \\
\mathrm{C}(1)-\mathrm{C}(3)-\mathrm{C}(5)-\mathrm{C}(4), \mathrm{C}(1)-\mathrm{C}(3)-\mathrm{C}(6)-\mathrm{C}(3), \\
\mathrm{C}(2)-\mathrm{C}(5)-\mathrm{C}(3)-\mathrm{C}(6), \mathrm{C}(2)-\mathrm{C}(5)-\mathrm{C}(4)-\mathrm{C}(6), \\
\mathrm{C}(3)-\mathrm{C}(5)-\mathrm{C}(4)-\mathrm{C}(6) ;
\end{gathered}
$$

- Ladenburg's configuration contains two rings of size 3:

$$
\mathrm{C}(1)-\mathrm{C}(2)-\mathrm{C}(3) \text { and } \mathrm{C}(4)-\mathrm{C}(5)-\mathrm{C}(6)
$$

and three rings of size 4 :

$$
\begin{gathered}
\mathrm{C}(1)-\mathrm{C}(3)-\mathrm{C}(6)-\mathrm{C}(4), \mathrm{C}(1)-\mathrm{C}(2)-\mathrm{C}(5)-\mathrm{C}(4), \text { and } \\
\mathrm{C}(2)-\mathrm{C}(3)-\mathrm{C}(6)-\mathrm{C}(5) .
\end{gathered}
$$

Comment. It should be mentioned that without the symmetry requirement, there are configurations without rings, e.g., the following one:

$$
\mathrm{CH}_{2}=\mathrm{C}=\mathrm{CH}-\mathrm{CH}=\mathrm{C}=\mathrm{CH}_{2} .
$$

\section{Acknowledgments}

This work was supported in part by the National Science Foundation grants HRD-0734825 and HRD-1242122 (Cyber-ShARE Center of Excellence) and DUE-0926721.

The authors are thankful to Yakov Ben-Haim for valuable discussions.

\section{References}

[1] H. E. Armstrong, "An explanation of the laws which govern substitution in the case of benzenoid compounds," Journal of the Chemical Society, 1887, Vol. 51, pp. 258-268.

[2] A. K. L. Claus, Theoretische Betrachtungen und deren Anwendungen zur Systematik der organischen Chemie, Freiburg, Germany, 1867 (p. 207). 
[3] J. Dewar, "On the oxidation of phenyl alcohol, and a mechanical arrangement adapted to illustrate structure in the non-saturated hydrocarbons," Proceedings of the Royal Society of Edinburgh, 1867, Vol. 6, pp. 82-86.

[4] R. Feynman, R. Leighton, and M. Sands, The Feynman Lectures on Physics, Addison Wesley, Boston, Massachusetts, 2005.

[5] T. C. Hales, "The Honeycomb Conjecture", Discrete and Computational Geometry, 2001, Vol. 25, pp. 1-22.

[6] J. F. Harris, Carbon Nanotube Science: Synthesis, Properties and Applications, Cambridge University Press, Cambridge, UK, 2011.

[7] F. A. Kekulé, "Sur la constitution des substances aromatiques", Bulletin de la Societe Chimique de Paris, 1865, Vol. 3, pp. 98-110.

[8] F. A. Kekulé, "Untersuchungen über aromatische Verbindungen", Liebigs Annalen der Chemie und Pharmacie, 1866, Vol. 137, No. 2, pp. 129-136.

[9] F. A. Kekulé, "Ueber einige Condensationsproducte des Aldehyds", Liebigs Annalen der Chemie und Pharmacie, 1872, Vol. 162, No. 1. pp. 77-124.

[10] F. A. Kekulé, "Benzolfest: Rede", Berichte der Deutschen Chemischen Gesellschaft, 1890, Vol. 23, pp. 1302-1311.

[11] A. Ladenburg, "Bemerkungen zur aromatischen Theorie", Berichte der Deutschen Chemischen Gesellschaft, 1869, Vol. 2, pp. 140-142.

[12] J. Loschmidt, Chemische Studien, Carl Gerold's Sohn, Vienna, 1861.

[13] L. Meyer, Die Modernen Theorien der Chemie, 1884.

[14] J. R. Partington, A Short History of Chemistry, Dover, New York, 1989.

[15] A. J. Rocke, "Hypothesis and Experiment in the Early Development of Kekule's Benzene Theory", Annals of Science, 1985, Vol. 42, No. 4, pp. 355381 .

[16] A. J. Rocke, Image and Reality: Kekule, Kopp, and the Scientific Imagination, University of Chicago Press, Chicago, 2010.

[17] K. Tanaka and S. Iijima (eds.), Carbon Nanotubes and Graphene, Elsevier, Amsterdam, 2014.

[18] D. H. Wilcox and F. R. Greenbaum, "Kekule's benzene ring theory: A subject for lighthearted banter", Journal of Chemical Education, 1965, Vol. 42, No. 5, pp. 266-267. 